This item was submitted to Loughborough's Research Repository by the author.

Items in Figshare are protected by copyright, with all rights reserved, unless otherwise indicated.

\title{
Women, sport and gender politics in Taiwan
}

PLEASE CITE THE PUBLISHED VERSION

http://routledge.com/9781138895720

PUBLISHER

Routledge

VERSION

AM (Accepted Manuscript)

PUBLISHER STATEMENT

This is an Accepted Manuscript of a book chapter published by Routledge in Women, Sport and Exercise in the Asia-Pacific Region on 27 Jun 2018, available online: http://routledge.com/9781138895720

\section{LICENCE}

CC BY-NC-ND 4.0

\section{REPOSITORY RECORD}

Chiang, Ying, and Alan Bairner. 2019. "Women, Sport and Gender Politics in Taiwan”. figshare. https://hdl.handle.net/2134/34553. 


\title{
Women, Sport and Gender Politics in Taiwan
}

\author{
Ying Chiang (Chihlee University of Technology, Taiwan) and Alan Bairner \\ (Loughborough University, UK)
}

\section{Introduction}

In debates on sport and nationalism in Western academia, women have generally been seen as being trapped in a marginalized position in relation to men.

However, modern sport, as a product of modernity, has transcended the historicity of Western culture. It is important, therefore, for non-western researchers to contrast their localized and gendered discourses on the same issue with those of their western counterparts.

Modern sport is simultaneously symbolic of both civilization and humiliation for many non-Western societies. However, sport itself is not a homogeneous concept; rather it is a highly contingent and contextualized practice. Constructing collective memories of sport are, therefore, important for non-Western researchers for developing localized understandings of sport with respect to 
specific cultural contexts (Chen, 2012a; Chiang, 2013).

Because critical and gendered examination of sporting culture is important for non-Western sport sociologists, acquiring a historical perspective can be a suitable way of achieving the necessary level of reflection. Tang (2009: 323) claimed that researchers should always pay close attention to the interrelations between local knowledge and Western modernity; the development of history should not be taken for granted. Thus, while Hargreaves (1990: 339) pointed out that "the history of women's sport can provide an understanding of the origins and causes of women's subordination in sport, and the nature of resistance to change and struggle for change”, it is vitally important that specific historical conditions are taken into account.

As a consequence of its belated modernity and multi-colonized history, modern Taiwan underwent the development and practice of sport differently from most Western societies. Nationalism underpins both the imagination and the practice of sport in Taiwan (Chiang, 2013). Indeed, it is impossible to capture the idea of sport in Taiwan without an understanding of Taiwanese nationalism and vice versa. In Western societies, sport and nationalism have typically stemmed from 
masculinized memory, masculinized humiliation and masculinized hope (Enloe, 1989; Benton, 1998). Meanwhile women have been trapped in a marginal position in the field of sport. However, the significant influence of Taiwanese sport nationalism has created empowerment opportunities for female athletes such that the history of Taiwan sport nationalism would be incomplete without the story of female athletes. In summary, the main focus of this chapter is on the collective memory of women and sport during the Martial Law era in Taiwan (1946 1973). In this respect, we are mindful of Ann Hall's (1985: 38) assertion that sport is an ideological institution with enormous symbolic significance that contributes to and perpetuates cultural hegemony. All the imaginations and representations of sport, sportswomen, and the life experiences and identities of female athletes reveal not only ideological domination but also the possibility of empowerment. In addition, towards the end of the chapter, we consider the development and contemporary experience of the daily consumption of leisure sport by Taiwanese women from the 1980s. Throughout the chapter, we subject to critical discourse analysis multiple genres of texts, including newspapers, TV programmes, government publications and the speeches of the architect of Martial Law, the Kuomintang (KMT) President Chiang Kai-shek, in an attempt to establish the contours of the collective memory of women and sport in 
Taiwanese society throughout this entire period. In addition, we also briefly

consider the case of Chi Cheng, Taiwan's most celebrated female athlete to date, who was interviewed by one of the authors in 2013.

\section{Taking an Asian methodological turn: building a Taiwan perspective}

In the 1980s, Taiwanese social scientists started to advocate "the Sinicization of social and behavioral sciences" (Yang \& Wen, 1982). However, to "ask our own question” is an ongoing process of self-reflection in Taiwan's sociological research field. Ying-zhen Chen (1997) claimed that Taiwanese intellectuals were inclined to adopt a Western (especially American) perspective to reinforce their theoretical foundations. This was primarily caused by the impact of anticommunist sentiments in the 1950s when criticizing the United States was greatly discouraged. In these circumstances, academic fields in Taiwan lacked the capacity, knowledge and desire to engage in a critique of American neocolonialism. Instead, the United States was seen as symbolizing strength, civilization and progress by most Taiwanese. 'The best students study abroad (in the United States)' was a popular belief in Taiwanese society and specifically in the academic field. 
In response to the implicit devaluation of scholarship in Taiwan, some Taiwanese researchers began to propose the need to take "an Asian methodological turn” (Chen, 2006). According to Guang-xing Chen (2006: 6), critical discourses, which were based on Asian (non-Western) experiences, could form a new perspective for the interpretation of the global order. New questions would be asked. This was to be a process of spiritual, cultural, political and economic selfreflection on the historical relations between the Taiwanese people and their numerous colonizers. This could be arduous and painful, because it is a process of self-criticism, self-denial and self-rediscovery. In the end, however, it could result in dignified, subjective agency. As mentioned above, to 'ask our own question' is the core principle as well as the essential practice of this process of academic localization. Chen (2006: 21) argues that researchers should take an ‘emic’ position, focusing on local experience. Thus, question sensitivity in conducting research should be based on "de-imperialization". Claiming to take an Asian methodological turn himself, Chen (2006: 23) emphasizes the significant meaning of the Taiwanese experience:

Taiwan is the microcosm of the region's history. Taiwan was never a closed space but a consequence of the political and economic struggles of the East Asian region. It was influenced by mainland China before the 
$20^{\text {th }}$ century, colonized by the Japanese in the first half of the $20^{\text {th }}$ century and influenced by American hegemony in the second half of the $20^{\text {th }}$ century. This was the shared experience of the region. Thus, understanding the history of Taiwan is the way to clarify the interrelationship between East Asian countries.

The history of Taiwan was undoubtedly multi-colonized. After Japanese colonization, the KMT dictatorship declared Martial Law, which was not withdrawn until 1987 allowing for the emergence of today’s democracy. In this context, the Taiwanese people share diverse, sometimes even opposing, national identities with the relationship between sport and nationalism reflecting the social significance of this ambivalence. It has a dynamic history articulated according to different cultural and political powers. Thus, it is important for Taiwanese sociologists of sport to construct an interpretative understanding of their society, thereby ensuring the localization of sport sociology. Ye (2001) argues that localized research must be 'culturally relevant'. Two emancipatory meanings can be attached to localization; first, it is an expression of emancipation from academic Western-centrism, and, second, it allows for critical self-reflection on the part of researchers. In addition, 'localization' is not only a methodological practice but also an 
epistemological task. The 'local' theme and object of research alone are not sufficient conditions for localization (Ye, 2001: 121).

As a powerful ideological institution, modern sport helps to reproduce and strengthen traditional gender ideology. Feminist critiques of this situation have been significant, not least in North American sociology of sport. Nevertheless, as Hargreaves (1990) observed, there is still a general tendency to differentiate between men and women in sport, rather than to focus on the relations between them. This is certainly true in the case of Taiwan, with most Taiwanese sport researchers regarding gender more as a quantitative variable than an ideological institution.

Focusing on the sport research field of Taiwan, the two major journals are Sport \& Exercise Research and the Physical Education Journal, which are listed in the Taiwan Social Science Citations Index. Of the 132 articles published in Sport \& Exercise Research between 2012 and the first half of 2014, only four articles were based on a critical gender perspective. During the same time, out of 86 articles published in the Physical Education Journal, none of them adopted a feminist perspective. Thus, building a local and gendered sport discourse in 
Taiwan represents an attempt from multiple margins to be both critical and political.

What role, then have Taiwanese women played in the relationship between sport and nationalism in Taiwan? As mentioned above, nationalism is the undercurrent of the imagination and practice of sport in Taiwan. Overall the aim of this essay is to achieve a localized methodological approach to studying gender in relation to sport for which an understanding of the social structure of the aforementioned era and of the collective memory of sport and women are crucial.

\section{Methodology: capturing social memory}

The emergence of social memory as a key cultural and political concern in

Western societies is a relatively recent cultural phenomenon (Huyssen, 2003).

However, it has come to be regarded as the foundation of different modern identities. Taiwanese sociologist Zhi-Jie Tang (2009: 314) claimed that for nonWestern researchers, the localization of social studies depends on the formation of a "sociocultural history”. Popular, prevailing, multiple materials should be taken into account to capture the true social structure of the given era which the researchers wish to understand. Only by analyzing these data can the researchers 
comprehend the common ideas and thoughts of the time and produce culturally

relevant and locally focused discussion.

According to Bairner (2012), the concept of memory presents interesting ways of extending and broadening the sociology of sport field. Multiple data, such as sport stars' autobiographies, should be considered as vehicles for understanding the collective memories of sport and sport-related events in society. In this regard, Taiwanese sport sociologist Tzu-hsuan Chen (2012b: 273) has emphasized the importance of mass-media texts. Chen claims that media representations are myths which are taken to naturalize history. The media representations of sport and important sport events create social memory which can be twisted or rotated in such ways as to disrupt the consistency of history and memory. Chen (2012b: 267) claims that there has been a "mass communication turn” in sport sociology. He argues that by approaching sport and physical culture from the perspective of the sociology of memory and by examining the influence of mass communication and media on sport/physical culture, Taiwanese researchers will be better equipped to advance towards a native critical sociology of sport/physical cultural studies. 
As mentioned above, the aim of this chapter is to construct a localized discussion of the relationship between gender and sport in Taiwan history. To achieve this, media representations are the main texts that have been analysed. Multiple genres of texts were collected, including biographies of and an interview with the most important female athlete in Taiwanese history, Chi Cheng. In short, this study, the main aim of which is to generate a critical discourse, incorporated multiple qualitative research methods, including textual analysis and an in-depth interview.

As Yu-ling Lin (2007) proposed, the 'validity' of any piece of research does not rest on its 'objectivity' but rather on its ability to capture the ideology and power relations that lie between lines. For researchers, the research process and the type of data are not the main concern; what matter far more is the relationship between agents and social structures. According to Chen (2012b), 'valid' qualitative research might not be 'generalizable' but readers should be able to ‘empathize’ with its findings. Indeed, according to Guang-xing Chen (2006:

437), the quantitative paradigm, and the belief in 'objectivity' are consequences of imperialism and globalization. Furthermore, they are symbolic of the hegemony of a Western scientific rationale. Critical qualitative methodology is, 
thus, a form of resistance.

\section{Representations of women and sport in Taiwan during the enforcement of}

\section{Martial Law (1949 1987)}

In 2016, Tsai Ing-wen became the first woman to be elected President of Taiwan.

The extent to which this indicated a major shift in the country's gender politics

remains to be seen. After all, the influence of Confucianism, with its advocacy of a society organized on the basis of patriarchal power, remains strong (Tsai, 2006). However, analysis of the status of women in the field of sport in Taiwan offers interesting insights into the island's gender power balance. The discussion that follows assesses the degree to which Taiwanese female athletes have been able to emerge as sporting heroes of the nation and the ways in which the Taiwan media have represented the relationship between women and sport more generally.

As 'the other' in terms of a multiple colonized inheritance, persistent collective anxiety surrounds both sport and nationalism in Taiwan. According to Chiang (2014a), since the Japanese colonial period, modern sport has been a symbol of civilization, causing both humiliation and pride. In general, however, sport and 
physical education became significant means to achieve national goals, build shared national identity and arouse patriotism. Even today, the hunger for 'the glory of Taiwan' and nationalistic sentiments which suffuse this hunger still underpin the imagination and practice of sport in an anxious nation.

As a product of Western modernity, sport and nationalism have traditionally been male preserves with women playing the role of 'the other' (Chiang, 2014b).

However, in certain contexts, this gendered relationship between sport and nationalism can be subverted. With its multi-colonized history and its multiethnic groups, modern Taiwan has a very different 'national' story from most Western societies. The way that sport is articulated in relation to Taiwanese nationalism is also unique, creating, as it does, empowerment opportunities for female athletes. Thus, the history of Taiwan sport nationalism would be incomplete without the story of female athletes.

\section{The militarization of sport and physical education}

The period of Martial Law in Taiwan, which had implications for both sport and physical education, lasted from 19 May 1949 to 15 July 1987 (a total of 38 years 
and 57 days). While the current central authority for sport and physical education (PE) in Taiwan is the Ministry of Education, before 1974 it consisted of military agencies (Chiang, 2013). At the beginning of 1950, the KMT government released the 'Education Agenda during the Period of National Mobilization for the Suppression of Communist Rebellion'. According to this agenda, sport was synonymous with physical education. Furthermore, the highest goals of PE were ‘anti-communism’ and ‘national defence’' (Liu, 2007).

'Sport/PE to save the country' was a firm political conviction of the time. According to Shou-bin Su (2011), to a Taiwanese person today, sport and exercise are personal matters; however, it was once a political requirement. Taiwanese women were no longer binding their foot and exercising to achieve health was their patriotic duty (You, 2011). In 1942, the then-President Chiang Kai-shek gave a widely broadcasted speech on the occasion of a national anniversary:

I am deeply worried about and shamed by the physical weakness of our people. No matter your age or gender, everyone should exercise so that we may remove the stigma of being 'the sick man of East Asia' and become a strong and modern country' (cited in Li, 1976: 8).

According to this speech, sport and PE symbolized Western modernity in the 
eyes of the government. However, the regime also regarded the national 'other' to be Western modernity and imperialism in the face of which women had the same national responsibilities as men. Thus, sport and PE were the major means to consolidate patriotism amongst women as much as men.

The atmosphere of anxiety persisted. However, because in the 1950s, the Communist Party of China, instead of Western imperialism, became the major national 'other' for the government, anti-communism became the supreme goal of sport and physical education. The militarization of sport/physical education and education through sport became the two major goals in the development of sport and PE (Chang, 2009). In 1952, the China Youth Anti-Communist National Salvation Corps (CYACNSC), under the jurisdiction of the Ministry of National Defense was established ${ }^{1}$ and it became the central administration for the body discipline of young Taiwanese, male and female (Hwang, 2010). According to their levels of physical fitness, the Taiwanese were divided into the categories of 'youth', ‘soldier', 'warrior', 'hero', and 'national rescuer'.

In the 1960s, 'anti-communism' and 'national salvation' remained at the core of

\footnotetext{
${ }^{1}$ On August 28, 1989 the CYC became anon-governmental organization. On October 25, 2000, the CYC officially dropped "Anti-Communist" from its official name.
} 
sport and PE in Taiwan. On 25 October, 1961, Chiang Kai-shek delivered a

speech at the opening ceremony of the $16^{\text {th }}$ Taiwan Province Games. He called on the people to “defeat the regime of the People's Republic of China as they once beat Japanese colonization”. Throughout the 1960s, sport and PE were thus taken to be examples of the behavioural requirements of the 'decent citizen'. Furthermore, in 1968, the government released 'Daily life regulations of the citizen’ which identified 'decent sports', including ball games, archery, driving, boating, travel, fishing, hunting, boxing, swimming and dancing. In the same year, the Ministry of Education started to simultaneously promote 'sport for all' and 'elite sport'. "Playing for the national glory" in international contests now became the main goal of national sport policy (Su, 2011: 121).

\section{No more a 'Rou Nu Zi' (a 'weak woman')}

The unusual character of Taiwanese sport nationalism created opportunities for women to participate in sport with the CYACNSC being the major organization for young women's sport and outdoor activities. In 1953, women participated in the first Military Summer Camp. Those who joined in the mountain climbing camp were described as “the glory of women” (Taiwan Women's Writing Association, 1965: 315) and any woman who engaged in the CYACNSC camp 
earned the title of 'new woman':

The name of "rou nu zi (weak woman)" vanished. Trained by the CYACNSC, all these women became responsible, creative patriots (Taiwan Women's Writing Association, 1965: 317).

According to contemporary texts, the then government was in need of patriots and 'doing sport' became a governmental recognized activity for women during that era. In the sports field, women began to be represented as 'heroines' (of the nation). As the most important physical discipline organization, the CYACNSC became the major promoter of women's sports. Because nationalism underpinned the imagination and practice of sport in Taiwan at that time, women were no longer 'others' of sport. Instead, they were encouraged to do sport. 314,704 people joined the CYACNSC summer and winter camps in the first 13 years of the organization's history. However, men still comprised the majority with women only accounting for $30 \%$ of all the participants (Taiwan Women's Writing Association, 1965). Nevertheless, for the KMT government, 'the empowerment of women' was one of the greatest achievements in relation to the contestation of Japanese colonization. For Chiang’s government, “women took the same national responsibility as their male peers” (Taiwan Women's Writing 
Association, 1965: 2). At the $4^{\text {th }}$ National Games, 1930, Chiang through his speech outlined the sport/physical education policy of his government:

In China, we used to have only male sport/physical education. Today, we have many enthusiastic female athletes. It is huge for our Chinese nation. I wish all the women who participated in the games today stay healthy, work out regularly and keep as fit as men. This is the empowerment of women. It will help us to achieve gender equality. Women are the “mothers of our nation”, and they take great responsibility (cited in Li, 1976: 5).

The question remains as to how much this was simply government propaganda and how far the evidence of change was apparent to the general public.

One athlete who is able to reflect on this era perhaps more than any other is Cheng Chi. Born on 15 March, 1944 in Hsinchu, Taiwan, she was a highly successful Taiwanese track and field athlete. In 1963, she left Taiwan to study and train in the United States. She became an Olympic medalist in 1968, and was named the Associated Press Athlete of the Year for 1970. Undoubtedly, she is the most important female athlete in Taiwan's history. Furthermore, she was described as the sportswoman who always carried a national flag with her (Sports Affairs Council, 2011). Chi Cheng set seven world records in 100 yards, 100 metres, 200 metres, 220 yards, 100 metres hurdles and, from 1968, 
she became the most important role model for patriotic athletes of the nation.

Reflecting on the past, in an interview conducted by one of the authors in 2013, Chi Cheng expressed her views on the subject of national discipline. Asked to express what the 'nation' meant to her during her athletic career during the Martial Law era, she replied:

Honestly speaking, we were successfully brainwashed at that time. The country was the most important thing for us, even beyond our own family. We stood to attention when we heard the names of Dr. Sun Yet-sen or the president Chiang Kai-shek (Interview with Chi Cheng, 25 April, 2013).

However, her sporting success also opened up new opportunities and exposed her to new ways of thinking. On her initial experience of living in the United States, for example, she said,

The best thing ever happened to me was that I could go to the United States to study. I understood what democracy meant there. The first time I read Time magazine, I was shocked by the ironic representation of President John F. Kennedy. If we did that in Taiwan then, we would have been arrested and sent to prison. (Interview with Chi Cheng, 25 April, 2013).

From Chi Cheng's story, we discover that, as an elite athlete at that time, she was highly disciplined by nationalism in the sports field and in her personal life. However, at the same time, she was empowered by the same disciplined nationalism. She got the chance to study abroad which was important for her 
subsequent self-reflection. Meanwhile the media were also playing their part in highlighting the achievements of female athletes.

\section{Media representations of sportswomen}

On 28 April, 1962, Taiwan's first TV station was established. The government was the majority shareholder in Taiwan Television (TTV). Television Weekly was first published by TTV in the same year. TTV covered the preliminaries and reviews of TTV News and TV shows. According to Television Weekly, women were the target audience for sports show. Female viewers were represented as “enjoying working out” (Television Weekly, 8: 30, 3 December, 1962) and “enthusiastic baseball fans” (Television Weekly, 12: 6, 31 December, 1962).

Meanwhile, women were also represented as athletes, including ice-skaters (Television Weekly, 31: 14, 13 May, 1963) and the female motorcycle rider who claimed “motorcycling was good for health” (Television Weekly, 158: 29, 18 October, 1965). Young female gymnasts were also introduced on television shows (Television Weekly, 39: 42, 8 July, 1963).

In most sport and nationalism discussions, baseball has been taken to be the national pastime of Taiwan (Morris, 2011; Chen, 2012b; Chen, 2016). However, 
in the 1950s, women's basketball was the other most important sport practice at the national level. Significantly, unlike baseball, which was a legacy of Japanese colonialization, basketball was introduced to Taiwan in the 1940s by recent immigrants from mainland China.

From the 1950s, Taiwanese women's basketball achieved impressive results in Asia and became a matter of "national business” for the government (Television Weekly, 306: 4, 19 August, 1968). From 1965, the Oriental Women’s Basketball Team was the most notable female basketball team in Taiwan. In 1972, the whole team visited the United States and Latin America for 87 days and achieved 39 victories in 47 games. On 30 March, 1972, when the team arrived back at Taipei airport, they were welcomed by the orchestra of the Ministry of National Defense and delegates from the Ministry of Education, the Ministry of Foreign Affairs, and CYACNSC. The United Daily News's editorial of the day was headed, “The Oriental Women’s Basketball Team: the successful model”:

The Oriental Women’s Basketball Team has carried the national responsibility. They were encouraged by the national glory and the expectation of our people. Being brave, fearless and strong, they are the role model to us, both men and women. They represented the spirit of our destination of national revival. We are proud of them. (United Daily News, 30 March, 1972) 
According to the texts that have been analysed, therefore, elite female athletes no longer appeared to be the 'other' in the sports field of Taiwan because of the strong articulation of the relationship between sport and nationalism. As elite athletes, women could be national role models for everyone, both men and women. As described in the same editorial, "these female basketball players were as great as little league baseball players" and "they were all diplomatic fighters”. Zhu-ru Sheng, a senior sports journalist with TTV, who traveled with the team many times, described the vigour of female basketball in Taiwan in his autobiography:

Women's basketball and little league baseball were most important sports then. At that time people used to say that "the international status of Taiwan was dependent on young kids and women” (Sheng, 1995: 156).

In spite of their success in the sports field, however, these female basketball players were still trapped by traditional gender expectations. They were represented by one famous sports journalist as "girls who loved taking pictures" (Fu, 1972: 40). Despite the praise they received as national heroes, they had to sing and dance on TTV sports shows dressed in the traditional cheongsam (Television Weekly, 17 April, 1972, 497: 30). 
Because of the specific circumstances that have prevailed in Taiwan, leading female athletes have been accorded greater status than has normally been the case in other countries with very different histories in relation to the requirements of the nation. However, just as the election of a female president does not necessarily tell us all that we need to know about gender relations in Taiwan neither does a focus on elite female athletes alone. In the concluding section of this study, therefore, we turn our attention to the contemporary experience of sport and physical activity amongst Taiwan’s female population more generally.

\section{Healthism and the beauty myth: consumerism and Taiwanese women's leisure} sport

Before the rapid growth of consumerism, nationalism was the most important aspect of the imagination and practice of leisure sport in Taiwan. However, after the 1960s, capitalism and consumerism began to supersede the role of nationalism in Taiwan society (Hwang, 2011). After the 1960s, it was believed that the island had embraced consumerism and was transformed into a consumerist society. A collective desire for consumption had emerged (Lee, 2011). 
From the perspective of the sociology of sport, sports and leisure are necessary components of the structure of contemporary sex/gender identities, life styles, and communities. According to Louise Mansfield (2013), a lifestyle politics promoting individual responsibility for health and fitness emerged in Western societies in the 1980s. In the case of Taiwan, people did not start doing exercise/sport for fun until the 1970s and, even then, private sports centres and gyms were regarded "imported spaces”. Thus, "sport for health and leisure” or "sport for fun” were seen as foreign or immigrant leisure ideas and forms of practice by the Taiwanese (Chiu, 2003).

In Taiwan, the predecessors of fitness centres and gyms were the dance studios in southern Taiwan which sprung up in the 1970s. Taiwanese women, but only women, could also learn aerobics in beauty salons in this era. In the 1980s, the first fitness centre was founded in Taipei by an American businessman, Clark Hatch, and was called the Clark Hatch Executive Fitness Club. In the beginning, most of its customers were foreign businessmen working in Taiwan. Hatch himself is seen by many as a physical fitness missionary who explored Asia, encouraging people to improve their health through exercise and nutrition. The 
following year, the Jia Zih Eurhythmics Center, a fitness club for women only opened. Over the next ten years, several women only eurhythmics centres were founded. One of them changed its name to Alexander Health Club in 1993 and finally opened up to male members. From the 1990s, several international fitness chains, such as California Fitness, began to do business in Taiwan (Chao, 2007). According to Chiu's (2003) research, the development of exercise culture in Taiwan represents the importation of a 'Western lifestyle'. 'Doing sport' in sports centres became a fashionable lifestyle choice in urban areas such as Taipei City. Although women had tended to be taken as the "others" in the sports field, at least in western societies, the first target customers of these sport and fitness centres were Taiwanese women. Thus we can argue that, in the history of Taiwan’s leisure sport, there was a transition from women's exercise to public participation.

In the 1990s, Taiwanese sport sociologists described the consumption of private sports centres as a marker of “social distinction” for the Taiwanese middle class. Doing sports in sports centres rather than in the park or the campus was regarded as adopting a distinctive, fashionable, and even Western, lifestyle. Furthermore, 
doing sport was no longer a practice of patriotism, but a manifestation of personal and fashionable leisure choices (Chiu, 2003; Chen, 2006; Hwang, 2006).

From 1998 to 2006, former president, Ma Ying-jeou, then the Mayor of Taipei City and his government decided to establish municipal sports centres in an attempt to transform Taipei into a 'healthy city'. The aim was to build public sports centres in each of the city's 12 districts. During the ground-breaking ceremony for the Xinyi Sports Center, Ma announced,

I heard many complaints about people having nowhere to exercise. Now that we have made exercise facilities accessible and affordable there won't be any excuse for our residents to be lazy (Mo, 2007). In 2003, the first sports centre, Zhongshan Sports Center, was opened and 11 years later, in 2014, the 12th sports centre, Wenshan Sports Center, was completed, thereby finishing the grand project.

As mentioned before, there has emerged a politics of "individual responsibility for health and fitness" rooted in Western modernity and consumerism. We have also noted that sport was established on the basis of Western modernity. Thus, as 
the 'other' of inheritances, for Taiwanese, modern sport became a symbol of civilization. There was pressure to catch up with the Western forerunners. Elite sport had become a significant vehicle for achieving national goals, including a shared national identity. Leisure sports, on the other hand, are intended to help to create ideal, healthy, civilized citizens. Needless to say, not all of these new citizens are women.

According to the Taipei Metropolitan Government, the population of Taipei is about 27 million. More than 52\% of the citizens are women. However, according to the statistics, in 2015, among the 11-million users in 12 municipal sport centers, only $46 \%$ of the users were women. Nevertheless, "the female power" of sport was highlighted in recent years by media representation, with Taiwanese women being represented as enthusiastic, active consumers of leisure sport (Ye, 2016). According to Fitness Factory (2016), a sports gym chain in Taiwan, the number of its female members increased by $20 \%$ in 2016. Furthermore, based on the statistics from the 2015 National Survey on Sports Consumption Expenditures, $11.4 \%$ of Taiwanese women had bought workout programmes, compared with $7.6 \%$ of men. In addition, women were more willing (57.8\%) to buy more programmes than men were (26.9\%). The three major motivations for 
Taiwanese women to do exercise were to "keep in shape” (76\%), "get healthier" (60\%) and "lose weight" (54\%) (Chang et al, 2017).

Global sports brands have also begun to take Taiwanese women as their target consumers in recent years. For example, in 2013, Adidas created a Facebook fan page for Taiwanese women called “Adidas women in Taiwan” (@adidaswomentw) (translated as “Adidas Girl” in Mandarin). The main slogans of this page include“ I create. Get stronger together ( $\square$ )”, and “Sweat, fearless ( $\square \square \square \square \square \square \square \square \square \square \square \square$ )”. According to Lazar (2011: 37), consumer beauty advertisers link the normative practice of beautification with an emancipated identity.

This approach maintains the connection between beautification and femininity construction, but resignifies the latter as productive of a 'new' kind of femininity that blends with feminist consciousness.

Furthermore, the consumerist discourse of emancipation is strikingly universal (Lazar, 2011: 49). Thus, despite the specificity of Taiwan’s history having affected in a positive manner the opportunities for female empowerment at the elite level, the uptake of leisure activities by the general female population may well represent the restoration of the hegemony of Western modernity albeit by a novel route (Yu et al, 2004, Tsai, 2009). 
In their advertisements in Taiwan, sports brands have presented exercise to be a symbol of female emancipation. Women have been represented as sweaty and sporty. At the same time, these campaigns also portray that "doing sport” can help women to "end their single life”, “enjoy food without gaining weight” and "get nice firm abs". Most of these advertisements still reproduce a homogeneous frame of reference of body shape, size, appearance and life style. Homogeneity is at the core of all the struggles between women and their bodies (Chiang, 2016).

\section{Conclusion}

The marginal position of nationalism and sport of Taiwan during the Martial Law era created the chance of empowerment for female athletes. They could be 'national heroes', participating in national narratives. They could play the roles not only of wives, mothers or daughters, but also of soldiers, warriors and fighters, and could even gain political influence, as Chi Cheng did after her retirement from track and field. Nationalism remains the undercurrent of the imagination and practice of sport in Taiwan; it is difficult to capture the essence of sport in Taiwan without understanding this relationship. As a highly significant figure in Taiwanese sport nationalism, Chi herself opened up 
empowerment opportunities for other female athletes. The history of Taiwan sport nationalism would be incomplete without the story of female athletes.

In addition to the requirements of nationalism, however, Taiwanese women today are also important consumers of leisure sport. "Doing sport” has become an important way to display their identities and lifestyles. We do not take women's participation in and consumption of leisure sports as unequivocally empowering, because attention must be paid attention to social class, globalization, and gender power relations involved in the practice and interpretation of leisure sports in specific societies. However, more and more Taiwanese women do assert that they love doing sport and exercise, not just as a mission, a burden or a form of discipline but also an important means by which to achieve fitness, health and pleasure. 


\section{References}

Bairner, A. (2012). For a sociology of sport. Sociology of Sport Journal.

29, 102-117.

Benton, S. (1998). Founding fathers and earth mothers: women's place at the 'birth’ of nations. In N. Charles \& H. Hintjens (Eds.), Gender, ethnicity and political ideologies (pp. 27-45). London, UK: Routledge.

Chang, M. Y. (2009). The history of physical education in Taiwan. Taipei, Taiwan: Wu Nan Press.

Chang, Y, Lin, P. H. \& Sogawa, T. (2017). Belly dancing as exercise: imagebuilding of a foreign dance in Taiwan. Asia Pacific Journal of Sport and Social Science. Forthcoming.

Chao, L. Y. (2007). The development of gym in Taiwan. [Online forum comment], 2 April. Retrieved from http://www.npf.org.tw/2/1820.

Chen, D. J. (2006). Constructing of Young Women's Body Concept in Fitness Gyms. Research Center of Gender and Space. 6, 83-111.

Chen, T. H. (2012a). Toward a critical sociology of sport / physical cultural studies. Physical Education Journal, 45(4), 267-278.

Chen, T. H. (2012b). From the "Taiwan Yankees” to the New York Yankees: the glocal narratives of baseball. Sociology of Sport Journal, 29, 546-558. 
Chen, T. H. (2016). How does a loser win? Taiwan and Global Sport. In J. Kelly,

A. Bairner \& J.W. Lee (Eds.), Routledge Handbook of Sport and Politics (pp. 496-506). London: Routledge.

Chen, Y. Z. (1997). The Americanization of Taiwan. Introduction to Dan, Y. (1997). The fifteen letters to Wen Qi. Taipei: Renjian Press.

Chen, G. X. (2006). Deimperialism: taking an Asian methodologically turn. Taipei: Editions du Flaneur.

Chiang, Y. (2013). Multiple margins: gender, sport and nationalism in Taiwan (Unpublished doctoral dissertation). National Taiwan Sport University, Taipei, Taiwan.

Chiang, Y. (2014a). The Other of Inheritances: the collective anxiety of sport and nationalism in Taiwan society. Taiwan: a radical quarterly in social studies, 100, 3-52.

Chiang, Y. (2014b). Not a stepchild to feminism: Gender mainstreaming in sociology of sport. Sports and Exercise Research, 16(4), 366-377.

Chiang, Y. (2016). The contradictory complex between women and sport.[ Online forum comment], 11 October. Retrieved from http:// twstreetcorner.org/2016/10/11/ying-chiang/

Chiu, C. C. (2003). The culture study of recreational fitness and lifestyle 
(Unpublished Master’s thesis). National Taiwan Normal University, Taipei, Taiwan.

Enloe, C. (1989). Bananas, beaches and bases: making feminist sense of international politics. London, UK: Pandora Press.

Fitness Factory (2016). The women fever: fitness is the key. [Online forum comment]. 6 May. Retrieved from http://fitness.thenote.com.tw/news/detail/2566/\%E5\%A5\%B3\%E5\%8 A\%9B\%Е7\%86\%B1+\%Е5\%81\%A5\%Е5\%BA\%B7\%E7\%BE\%8Е\% E6\%89\%8D\%E6\%98\%AF\%E7\%8E\%8B\%E9\%81\%93\%EF\%BC\% 81

Fu, D. R. (1972). The note of the America tour II: Olive and coffee. Television Weekly, 491, 40-41.

Hall, M. A. (1985). Knowledge and gender: epistemological questions in the social analysis of sport. Sociology of Sport Journal, 2, 25-42.

Hargreaves, J. (1990). Gender on the sports agenda. In E. Dunning \& D. Malcolm. (Eds.), Sport: critical concepts in sociology, volume 1 (pp. 324346). London, UK: Routledge.

Hwang, J. L. (2011). History, body and nation/state: the formation of body in modern China, 1895-1937. Taipei: Linking. 
Hwang, J. L. (2010). The civil right and the civil body. In J. L. Huang, H. L.

Wang, and C. X. Huang (Eds.), The Margin of Empire (pp. 251-281). Taipei, Taiwan: Socio Publishing.

Hwang, S. T. (2006). Unsatisfied desire and its possibility: gendered exercise and space. Research Center of Gender and Space. 6, 53-82.

Huyssen, A. (2003). Present pasts. Urban palimpsests and the politics of memory. Stanford, CAL: Stanford University Press.

Lazar, M. M. (2011). The right to be beautiful: postfeminist identity and consumer beauty advertising. In R. Gill \& C. Scharff (Eds.), New Femininities: Postfeminism, neoliberalism and subjectivity (pp. 37-51). London, UK: Palgrave Macmillan.

Lee, Y. Y. (2011). Consumption and Daily Life. In Y. H. J. (Ed.), The history of Republic of China (pp. 589-619). Taipei, Taiwan: National Chengchi University

Li, Y. X. (1976). President Chiang Kai-shek's instruction in physical education. Taipei, Taiwan: Republic of China Sports Federation.

Ling, Y. L. (2007). Schoolchildren's game-playing practices and gender construction: A case study of elementary school pupils in a remote area. Mass Communication Research, 90: 43-100. 
Liu, Z. Y. (2007). Taiwan: women and physical education (1895 2006)

(Unpublished Master’s thesis). National Taiwan Sport University, Taipei, Taiwan.

Mansfield, L. (2013). 'Sexercise’: Working out heterosexuality in Jane

Fonda’s fitness books. In J. Caudwell and K. Browne (Eds.), Sexualities, spaces and leisure studies (pp. 139-158). New York: Routledge.

Mo, Y. C. (2007) Feature: Taipei's municipal sports centers energize residents. Taipei Times, 27 February. Retrieved from http://www.taipeitimes.com/News/taiwan/archives/2007/02/27/20033502 17

Morris, A. D. (2011). Colonial project, National Game: A history of baseball in Taiwan. Berkeley: University of California Press.

Sports Affairs Council (2011). The oral-history of elite athletes: Chi Cheng. Taipei, Taiwan: Sports Affairs Council.

Sheng, Z. R. (1995). In front of the silver screen: autobiography of Sheng Zhuru. Taipei County: The Journalist.

Su, S. B. (2011). Leisure, Sport and Tourism. In Y. H. Zhang (Ed.), The history of Republic of China (pp. 621-653). Taipei, Taiwan: National Chengchi University. 
Taiwan Women's Writing Association (1965). Taiwanese women in the last two decades. Taipei, Taiwan: Taiwan Women's Writing Association.

Tang, Z. J. (2009). The discussion on the research of sociocultural history. In C.

X. Zou \& F. S. Su (Eds.), The reflection and insight of the localization of social studies (pp: 313-366). Taiwan: Nanhua University

Television Weekly (1962). The Schedule of Sport Shoes. 3 December, 8, 30.

Television Weekly (1962). Baseball: Waseda vs. Keio. 31 December, 12, 6.

Television Weekly (1963). Golden age: the Swan ice-skating team. 13 May, 31,

14.

Television Weekly (1963). Skill sports. 8 July, 39, 42.

Television Weekly (1965). Today sports: motorcycling. 18 October, 158, 29.

Television Weekly (1965). Today sports: women football. 22 November, 163, 47.

Television Weekly (1968). FIBA Asia Championship for Women.

19 August, 306, 4-10.

Television Weekly (1972). The sidelights of TTV. 17 April, 497, 30.

Tsai, C.T.L. (2006). The Influence of Confucianism on Women's Leisure in

Taiwan. Leisure Studies, 25, 4, 469-476.

Tsai, C.T.L. (2009). Media systems and their effects on women's sport participation in Taiwan. Sport, Education and Society, 14, 1, 37-53. 
United Daily News (1972). The Oriental Women’s Basketball Team: the successful model, 2, 30 March.

Yang, G. S. \& Wen, C. Y. (Eds.), (1982). The localization of social and behavioral sciences studies. Taipei, Taiwan: Institute of Ethnology, Academia Sinica.

Ye, H. H. (2016). Gym program only for women. Economic Daily News. 14 August. Retrieved from: https://udn.com/news/story/7241/1893671

Ye, Q. Z. (2001). Sociology and Localization. Taipei, Taiwan: Jyuliou.

You, J. M. (2011). Be ourselves: Women and the Republic of China. In Y. H. Zhang (Eds.), The history of Republic of China (pp. 275-307). Taipei, Taiwan: National Chengchi University.

Yu, C. C., Liaw, Y. H. \& Barnd, S. (2004). Cultural and social factors affecting women's physical activity participation in Taiwan. Sport, Education and Society, 9, 3, 379-393. 